\title{
Historical Comparison Re-considered
}

\author{
Reza Azarian \\ Stockholm University, Sweden \\ E-mail: reza.azarian@sociology.su.se \\ Nadezda Petrusenko \\ Södertörn University, Sweden \\ E-mail: nadezda.petrusenko@sh.se
}

Received: February 18, $2011 \quad$ Accepted: April 27, $2011 \quad$ doi:10.5539/ass.v7n8p35

\begin{abstract}
Comparative analysis is a mode of research, that due to its outstanding merits is widely used within many fields of scientific inquiry. Focusing on its application in historical research, this article aims to contribute to a more systematic discussion of some of the methodological strategies associated with this mode of analysis. For this purpose, this article presents first a few typologies regarding the functions and leverages of comparative analysis. In the next step different styles in which comparative method is applied are exemplified, with especial attention paid to the comparative studies of large-scale, macro-level societal changes. This article ends then with a critical discussion of the potentials and limitations of comparison as a methodological strategy of generating historical generalisations.
\end{abstract}

Keywords: Development, Euro-centrism, Historical generalisations, Modernisation, Social change

As a scientific method, comparison refers to the research approach in which two or more cases are explicitly contrasted to each other with regard to a specific phenomenon or along a certain dimension in order to pinpoint otherwise unobservable similarities and differences among the cases; and as a method strategy, comparison plays an important part in the most diverse branches of the humanities and the social sciences alike. Whereas its early intellectual roots go as far back as to the Antiquity, this mode of inquiry seems for the present to be more fashionable than ever before, as it is industriously applied in nearly all disciplines and applied to the study of almost any topic, including the study of the working conditions across nations, differences of life values within a single societal context, contrasts of face-work in various cultures, varieties of written documents in different countries, and much more (Allik, et. al. 2010; Drobni, et. al. 2010; Droogers 2005; Magun \& Rudnev 2010; Merkin \& Ramadan 2010; Suzuki 2010). Yet, despite this widespread and inter-disciplinary application, regretfully little attention is paid to this method as such, and it is only occasionally that the potentials and limitations of this strategy receive adequate treatment in social scientific method textbooks. Given the insufficient attention paid to various methodological questions linked to the use of comparison, the present article aims to discus some aspects of the question. The overall ambition and the chief purpose here is to contribute to the systematic and serious treatment that the issue of comparison deserves by exploring the special conditions and possibilities as well as the particular difficulties and limitations of this method to generate scientific knowledge.

The chief objective of the article is sought by exploring the various theoretical functions attached to comparison as a method strategy. It therefore begins with a short history of this method, demonstrating the variety of its uses in classical and modern social thought. The article then proceeds by discussing the common purposes normally pursued by its application, using some of the existing typologies and exemplifying each mode of application by a few well-known cases of comparative analysis. In the last section some of the problems associated with this method are discussed and, finally, some tentative remarks conclude this article. For a systematic presentation of the various ways in which comparative research is commonly conducted a particular typology is used here. This typology is borrowed from Tim May (1993) and is contrasted with a couple of other ones, offered by some of the prominent practitioners of comparative research such as Theda Skocpol and Charles Tilly. Furthermore, a number of well-known comparative studies belonging to different disciplines are used in order to demonstrate 
and examine the aims that comparative researchers often pursue and the way they actually carry out their comparative research.

\section{Comparison: A Common Method Strategy}

The use of comparison in the study of human society, history and culture has a long history. The legacy of comparative work in the field of social theory is traceable to the Greek Antiquity. Never declined, this sustained tradition has since then been only reinforced as the time has passed, and today due to certain historical developments like the enormous increase in communications, technological advances and the immanent intensification of internationalisation tendencies, comparative research, comparative research - in particular especially cross-national comparison - appears more appealing than ever, with the result that the bulk of contemporary human and social sciences abounds with examples of comparative approaches. However in this section we shall just take a brief look at a rather arbitrarily chosen set of studies, belonging to different fields, in which this method strategy has been adopted, and this is done merely in order to demonstrate the spread and general applicability of comparison across disciplinary boundaries.

An illustrative example is to be found in Alexis de Tocqueville's two much-celebrated studies - Democracy in America and The Old Regime and the French Revolution. Although these works are essentially comparative the author carries out his analysis without elaborating explicitly on his methodology, and uses comparison in an unsystematic and impressionistic fashion. The question that primarily preoccupies the author in these studies is to provide an explanation of the rise of democracy and social equality by comparing two extreme cases: First, he looks toward the United States of America which in his view represents an approximation to the pure case of democratic society where the social evolution toward equality seems to have reached its 'natural' limits. Here the special law of inheritance induces equal partition of property whereas for instance in France - an approximation to the pure case of a society organised along aristocratic principles - the equivalent law makes necessary a division of land among the members of the family.

In Max Weber's well-known work, The Protestant Ethics and the Spirit of Capitalism, on the other hand we find more stringent use of comparison in the social sciences. Here Weber, in polemic with Karl Marx, aims to provide a fuller and more comprehensive explanation of the emergence of the modern rational capitalism, and to serve this end he undertakes a large-scale, wide-ranging comparison of West with other civilisations of the world. Rather than refuting all together Marx's theory that emphasises the importance of economic factors, Weber demonstrates that the rise of Western capitalism can not exclusively be explained in terms of purely economic forces. On the basis of his famous historical comparison he assets instead that, in addition to such forces, what also is needed for rational capitalism to emerge is the particular ethics, that is a special and rather unusual ethics derived from the Calvinistic doctrine of predestination existing only in some parts of the West at the dawn of modernity. By using comparative method Weber demonstrates that whereas in economic and political terms China (and perhaps India) did not lack many of the societal factors necessary for the development of rational capitalism, it did not possessed the particular religious spirit that was characteristic of Calvinism (Parsons 1968).

Emile Durkheim (1982: 147) represent another example. Elaborating on the methodological principles of the embryonic discipline of sociology he for instance holds that "since social phenomena clearly rule out any control by the experimenter, the comparative method is the sole one suitable for sociology." Or as he (1982: 157) puts more outspokenly on another occasion, "comparative sociology is not a particular branch of sociology; it is sociology itself, in so far as it ceases to be purely descriptive and aspires to account for facts." This position was clearly demonstrated in practice when he in his classical study of suicide uses a comparative approach and reveals that far from being a private act of isolated individuals, suicide is a social phenomenon with rather stable observable regularities, challenging thus successfully psychological accounts of the phenomenon and establishing sociology as a distinct academic discipline in it sown right.

The vast body of literature dealing with the general question of modernisation and its multiple dimensions hosts a large number of comparative works. A chief underlying theme in many such works concerns the question as to what extent it is justified to speak of a universally valid model of, and a general common path to, modernisation. Most comparative studies belonging to this line of work aim usually to explore different national development paths in order to unearth similarities and differences among comparable cases. An influential work in this regard is Dynamics of Modernisation (1967) by Cyril Black who rather ambitiously develops a paradigm for doing comparative research. Drawing on a number of modernisation theories, the author aims in this book to map out and describe several distinct general features of this large-scale process through which old institutions such as state and family re-adjust to new societal functions. 
Other examples are to be found in the classical works of Walt Rostow and Alexander Gerschenkron where comparative method is used in order to underpin the attempts to elaborate empirically founded theories of economic development in general and industrialisation in particular - evidently a central theme vividly debated in the studies of modernisation. In his influential study from 1960 - The Stages of Economic Growth - Rostow puts forth an interesting theory of industrialisation derived from comparing a number of countries with various experiences of economic development. At the heart of this theory lies the identification of a number of stages or phases through which every industrialising country is bounded to pass on its way towards modernity. According to this general scheme of development each nation has necessarily to go through a certain set of phases and face a certain set of challenges to which there exists a certain set of solutions. This kind of deterministic, stage-theories - at least in their explicit forms - are of course almost totally out-dated yet at the time of publication the book enjoyed much attention and proved to have not insignificant impact which ways underpinned by strength of the comparative arguments that Rostow had argued for his universal roadmap to modernity.

In the same fashion Gerschenkron aspires to develop a theory of a normal or standard path to modernisation with a universally recurrent sequence of phases, and to this end he embarks on a comparative analysis in order to discover the fundamental features of the industrial development common to the European cases. The core idea underpinning the theory presented in his Economic Backwardness in Historical Perspective (1962) in other words is the comparison between various European industrialisation processes with the aim of finding fundamental similarities and significant differences that can be generalised. On the basis of the comparisons make he distinguishes between the two groups of 'early' and 'late' developing nations, and maintains that the dynamics, rhythms and mechanisms of economic growth vary systematically between the two, paying especial attention to the role of the state who in the lace of the late-comer nations appears to play a larger, more active and direct part in the accumulation and investment of capital.

Another common topic in the context of modernisation theories is the so-called German Sonderweg (literally, the German special path) thesis, which was worked out by the German historians of the nineteenth and early twentieth century chiefly in order to underscore the particularity of the German case. Accordingly the German path to modernity illustrates a historical singularity, i.e. a historically unique phenomenon diverging from and even in some respects contrasting to what has been the common path of other Western countries to modernity. Underpinned by comparative analysis the core of the theory consists of highlighting some of the special geographic and historical situation of the country including Germany's pronounced statism in contrast to Western parliamentarism, the German Kultur as opposed to the Western Zivilization, and the early development of the social welfare system in Germany in contrast to the economically liberal laissez-faire of the West (see Kocka 1999. For a similar kind of work dealing with the particularity of the United States of America see Lipset 1996).

And finally, European revolutions constitute yet another phenomenon in the context of modernity that has frequently been the subject of trans-national comparative examination. Among the important cases are: Barrington Moore's Social Origins of Dictatorship and Democracy (1966), Jack Goldstone's Revolution and Rebellion in the Early Modern World (1991), Charles Tilly's European Revolutions (1993) and Theda Skocpol's States and Social Revolutions (1979) (see below). More recently, however, we have witnessed a powerful renewal of interest in political economy, i.e. the tradition typically characterised by the insight that economic life is constituted by and through power relations, suggesting that, therefore, it can be best understood by learning about the power structures and strategies prevalent in society at large. Central to this research current is the observation that among the Western welfare states there is by far more variation than their structural similarities may suggest. And against this background, quantitative cross-national comparison is adopted by this tradition as the most fruitful methodological strategy (See Shalev 1996; Janoski \& Hicks 1994; Kindleberger 2000).

\section{Comparative Analysis as a Research Strategy}

Comparing like and unlike phenomena is a natural and elementary function of human mind. It is one of the most fundamental, generative perceptual processes which underpins much of our faculty of reasoning. This ability is so crucial to our cognition that it is almost impossible to think without comparing. Nonetheless, in itself comparison is far from being reliable as a method of producing scientific knowledge, and unless it is disciplined along rules of science its results do not qualify as scientific. Therefore this section is devoted to the presentation of some of the principal insights and arguments dealing with the scientific value of comparison. This section also highlights some of the necessary conditions needed for safeguarding the scientific quality of the knowledge generated through comparative analysis. 
In general terms, comparison is a mode of analysis that is often regarded as a method of the explicit contrasting of two or more cases in order to explore parallels and differences among them. Cases are frequently compared with regard to a specific phenomenon, like nation-building process, revolution, institutional framework, etc. It is not uncommon that chief purpose of such a comparison is to arrive at a typology derived from the systematically observed differences and similarities among cases, even though to acquire a better and deeper understanding of singular cases also may figure as a major purpose in many comparative studies. Historical comparisons in particular are mainly synchronic but sometimes diachronic in that they involve events, processes and/or social institutions belonging to different periods in time. In general, however, historical comparative studies are typically international, although sometimes they are carried out at national or even regional level. Occasionally, entire civilisations or cultural spheres make up the units of analysis. And finally, comparisons usually concentrate on a limited number of cases even though all-inclusive approaches, embracing all the existing cases, are not too uncommon.

More exactly however comparative analysis s a style of scientific inquiry analysis in which two or more entities are systematically investigated with regard to their similarities and differences in order to arrive at a deeper understanding or a better explanation. So defined this mode of analysis is to be distinguished from those considering only one entity or phenomenon as well as from those that aim for acquiring knowledge about the mutual influences and the interplay between two or more units of study. Furthermore, as the definition above indicates, comparison is not an end in itself but serves other objectives, and consists of a variety of approaches each with a particular set of functions and ambitions attached to. Therefore, as Jurgen Kocka (1996: 197-8) phrases it, comparative studies should be reflexive in that it should be clear "why what is being compared with what, in what respect and with what aim." Therefore, against this background, it seems plausible to start by considering the various functions and purposes usually attached to comparison.

Let us begin by presenting two extreme positions on the matter. On the one end there is the positivistic view, perhaps best represented by Neil Smelser (1976: 2-4) who maintains that in fact there exists no real ground for speaking of comparative analysis as a distinct mode of inquiry. Apparently drawing on Durkheim, Smelser is in other words of the view that the analysis of evidently dissimilar units does not present any methodological problems unique to itself and that all the difficulties that may appear in such an analysis are basically the same as those in all other types of social scientific inquiries. It is therefore hardly surprising that comparison has been widely used in all social scientific disciplines from the beginning and still does. Yet, there are nonetheless some specific features to the comparative study of dissimilar social entities, according to Smelser. First, it may be justified to use comparison as a less adequate substitute for experimental research and/or statistical analysis since it is nearly impossible to manipulate social phenomena as in an experiment and/or there may not be enough cases to make statistical inferences that are meaningful enough; Secondly many methodological problems - such as establishing equivalent measures or controlling for the third variable - may stand clearer to the investigator once a comparison is designed.

On the other hand there is the other extreme position, usually taken by historians, that is characterised by the emphasis on the distinct nature of the human sciences, different from the natural ones, rejecting thus the applicability of the methodological rules of the latter group to the former. Endorsing the idea of uniqueness of historical processes, historians frequently questions the adequacy of comparison as a research strategy and discard its potentials for generating reliable knowledge especially law-like causal patterns and regularities. In their view every historical event or situation contains not only one given but a number of potential possibilities that cane be realised, and knowledge about some initial conditions is never sufficient to assert which one of these possibilities is to be realised or how the specific situation under observation will unfold, dismissing thus the notion of historical development along any predicted path and/or according to any presumed order. The point is aptly expressed in the words of Gerschenkron (1966: 5) for instance who - referring to the old fashion grandiose attempts of earlier social thinkers like Herbert Spenser, August Comte, Karl Marx and others to discover universal patterns of social change and development - asserts that modern historians have grown modest and have abandoned the "prophetic flavour" and the "childlike faith" of their predecessors "in a perfectly comprehensible past whose flows were determined by some exceedingly simple and general historical law."

Leaving these two extreme standpoints aside however, there is a range of positions concerning the scientific worth and usefulness of comparison as a mode of analysis. Indeed most comparative studies carried out can be located between these two extreme positions, and many comparative researchers have tried their hands at transcending the apparently uncompromising and artificially held dualism between them, aiming for more subtle insights based on the actual empirical comparative research. At any rather, as the debate on the potentials and 
limitations of the comparative method continues, several typologies have been developed on the basis on the possible leverages of this method in developing theories.

In the context of the methodological debates on comparison Charles Tilly is one of the major and most influential figures - a historically interested sociologist well known for a number of comparative studies on the early European modernity. In Big Structures, Large Processes, Huge Comparisons, now a modern classic on comparative method from 1984, he puts forth a four-folded typology which has been relatively well-received. There are of course a number of other typologies, for instance those developed by Charles Ragin (1987) and by Theda Skocpol and Margaret Somers (1978), but in the presentation below it is the typology offered by Tim May in Social Research (1993) that has functioned as the schematic device used to systematise the presentation of the various comparative strategies in use. Unlike the typology elaborated by Tilly, which is primarily developed with historical-sociological research in mind, May's classification of comparative strategies is of a more general character, and therefore chosen here. As we proceed however we try to draw a parallel between the two, pointing out the tangible substantive similarities between them.

\section{Identifying the Particularity}

For the purpose bringing some structure into the variety of valuations of comparison, May (1993:157) offers a four-folded typology, including the import-mirror view, the difference view, the theory-development view and, finally the prediction view. (Note 1) Accordingly, the he first category captures the general reflexive function of comparison, i.e. the function it has for the broadening our sight, widening our horizon and seeing things in perspective. It refers, in other words, to the view that suggests that comparative analysis is worthwhile because, by taking into consideration social actions and events belonging to other contexts, it enables us to see better the implicit and often taken-for-granted basis of our own practices and phenomena. According to May, whereas on "an instrumental level" the results generated by a comparative study may permit the importation of different methods of organising a society's affairs to improve their efficiency, it also makes us "reflect upon our own social systems and cultural ways of behaving." Comparison possesses, therefore, the potential of revealing and challenging our less evident assumptions and conceptions about the world, especially the familiar one of oneself.

A similar point is made by Kocka (1996: 202) who holds that "often the look into the other country, the other society, the other village or the other part of the world affords better understanding of one's own history." He refers to this kind of comparative analysis as the contrastive comparative method -a mode of analysis often motivated and adopted for the purpose of better grasping one's own peculiarity. In addition to the case of the so-called German Sonderweg (see above), Kocka mentions Protestant Ethic and the Spirit of Capitalism as an example of this kind of comparative study, arguing that in this work Weber looks comparatively at other civilisations mainly to gain insights about the particular development in his own occidental civilisation. Asking why similar phenomena did not occur elsewhere Weber is, Kocka holds, primarily interested in understanding better the path of Western development and the features and properties particular to that.

This kind of comparative analysis is labelled individualising comparison by Tilly (1984: 87-9) who, like Kocka, mentions Weber's comparison of the world religions as an attempt to specify the uniqueness of the West, never abandoning "the search for the secret of rationalism's triumph [there]." As another example, Tilly (1984: 90) names Nation Building and Citizenship where the author, Reinhard Bendix, compares Western Europe, Russia, Japan, German, and India, in order to specify the uniqueness of the process that in West alone led the creation of a national political community: a national state in which citizens had enough confidence in their rulers and their institutions that the rulers could handle change without destroying their capacity to rule. Bendix's another major work, Kings or Peoples (1978) too is mentioned by Tilly (1984: 91) as a case of individualising comparison where Bendix seeks to demonstrate and understand the uniqueness of the historical process that in the West, and only there, led to the establishment of popular sovereignty, by comparing it to the hereditary monarchy as the mode of rule prevalent in the rest of the world in the sixteenth century.

Used in this fashion, comparative analyses serve the more explicit profiling of individual, and often particularly interesting, cases. In doing so, they may prove to have what Tilly (1984: 145) calls a "rare clarifying power." Moreover, it may also serve the identification of problems and issues, which would not be seen without it, as one is led to assume something analogous should or might have taken place elsewhere. At any rate, this kind of comparison may prove useful in leading to posing significant and sometimes novel questions and, furthermore, can help place some local phenomenon in a broader context, serving thus as a kind of rough check on proposed explanations.

Yet, it should also be kept in mind that, as Kocka points out, this type of studies often tend to be rather asymmetrical. That is, frequently the other cases brought up for comparison are only roughly sketched and 
reduced to elements that make up a rather vague background against which the main case in focus can be contrasted. Therefore, as Weber's study illustrates this fully, the comparison is only hinted at and one cannot really speak of a fully-fledged comparative analysis. This point finds an echo in George Fredrickson (1997: 23) who makes a distinction between research that is truly comparative and one that uses comparison only in a relatively brief and casual fashion. Accordingly, many of studies that claim to be comparative are not so in the full sense of the term since they do not have as their main objective the systematic comparison of some process or institution across the compared units. Therefore, they are hardly much more than one-case studies that use some "exotic analogy" in order to shed additional light on the particular issue that lies in the centre of their attention.

\section{Unearthing Convergences and Deviations}

The second type of comparative studies are that clustered by May under the label of the difference view represents the mode of analysis that undertakes to explore, understand and explain differences across apparently similar units. An important characteristic feature in this type of studies concerns the revealing of divergences and variations within what is presumed to be a united and undifferentiated category of units. Given the fact that no social phenomenon or process recurs in the same form, this kind of comparison promises to help us make sense of the observed variations and capture the principles of both similarities and differences. In other words, a comparative examination is undertaken involving sufficiently similar entities but differing in the respect of a phenomenon of particular interest. Such a comparison of the phenomenon in question across various settings will thus, according to this view, enable us to see the divergent formations of the phenomenon and ask why some have developed in similar ways while others in different ways. These types of studies are by Tilly (1984:116) referred to as variation finding comparisons, understood as studies that through comparing multiple forms of a single phenomenon seek to unearth systematic differences among instances and establish a principle of variation in the character or intensity of that phenomenon.

An example here is Gösta Esping-Andersen's comparative study of the modern Western welfare states, from 1990. In this comparative study the author seeks to reveal the major differences among these apparently similar societies and to lay bare the fundamental properties that unite and divide them, developing a typology into which various welfare states are classified. Using a considerable amount of data and a set of ideal-typical welfare regimes (liberal, conservative and social democratic), he succeeds in showing how countries' welfare states have evolved as a result of different historical forces. (Note 2) Another example in this regard is Ian Taylor's volume (1990) where he sets to compare five Western-style societies in order to bring into light the variations among them, regarding the adoption of free-market policies. The focal point here is that comparison is used to illuminate the fact that these societies, due to their cultural specifities, respond differently to policies derived from the liberal doctrine of free market.

Yet another example here is Nancy Green's (1997) study of the modern Jewish Diaspora. Carrying out what she calls "divergent comparison", Green is mostly interested in demonstrating that, although Eastern European Jews who immigrated to the West remained for a while a single, firmly tied and undifferentiated ethnic community, they nonetheless relatively soon started to differentiate and, thereby, the group begun to disintegrated. Unsatisfied with the existing migration studies, the author deploys comparison to support her thesis and to demonstrate the actual differentiation among Jews along socio-economic and cultural dimensions; and by showing the relatively great importance of the actual life conditions she challenges the unwarrantedly presumed impact of an invariant ethnicity and the subsequent similarity of immigrant Jews all over the world.

A classical example here, however, is Moore's famous Social Origins of Dictatorship and Democracy from 1966, which deserves to be considered in more details. Comparing the agrarian sources of modernity in England, France, the United States, China, Japan and India, Moore endeavours in this book to explore the varied political roles played by the two major socio-economic classes of the pre-modern agrarian societies, namely, the landed upper class and the peasantry, in the transformation of these societies into modernity. The focal point in Moore's analysis is to explore how in each context, the landed social groups of objectively similar structural positions played different roles in responding to some common general societal transformation and how the actual paths and outcomes of the interplay of social forces turned divergent.

As Moore (1966: viii) declares, in some what more specific terms, the study is "an attempt to discover the range of historical conditions under which either or both of these rural groups have become important forces behind the emergence of Western parliamentary versions of democracy, and dictatorships of the right and the left, that is, fascist and communist regimes." Pursuing this end, he then distinguishes four distinct paths to the modern world: one leads to capitalist democracy by way of bourgeois revolution - as in England, France and the United States; 
a second to fascism as in the case of Japan (and Germany); a third path leading to communism through the revolutionary mobilisation of the peasantry, as in China (and Russia); and finally the abortive kind of development or stalled democracy, i.e. a democratic form without effective representation, as in India.

In conducting this comparative study, however, Moore (1966: xi) is rather modest and does not aim for more than arriving at new sound historical generalisations that, derived through induction, are only to provide us with a preliminary orientation, with a "sketch in a very broad strokes" or a "large-scale map of an extended terrain such as an airplane pilot might use in crossing a continent." Furthermore, he also asserts that while such a comparative analysis may help us come a step closer towards specifying configurations favourable and unfavourable to the establishment of modern Western democracy, it is obviously "no substitute for detailed investigation of specific cases" and can never be in place of causal explanations - a point that is in sharp contrast with the third type of comparative studies to be discussed below.

\section{Generating Causal Generalisations}

Finally, the third type of comparative studies consists of those with rather high ambition to use comparison in order to develop causal theories with considerable generality and wide range of applicability. In what May (1993: 157) calls the theory-development view, it is believed that comparative approach should not stop at mere description of differences and similarities and development of typologies. Rather comparison can and should be used to extract insights about the causal relationships responsible for the observed similarities and differences. In other words, the overall ambition here is not merely to identify the different actual or possible paths that social processes may take but to develop a causal theory that can explain most of, if not all, the cases under observation. Although the degree of generality and the scope of applicability of the developed theory vary, there is nonetheless the conviction that comparison can, and should, be used to arrive at causal models that transcend the particular cases from which they are derived.

This type of comparative analysis is labelled by Tilly (1984: 97) the universalising comparison. He also traces back this mode of comparison to the now out-dated natural history, an analytical tradition in which "the theorist would typically begin with a well-known instance (of any social phenomenon), break the experience of that instance down into a sequence or set of stages, then propose the extension of the sequence of stages to many instances - sometimes to every known instance." According to Tilly, this mode of analysis is characterised by a systematic comparative examination of the chosen cases, which stand as logically independent instances of the same phenomenon. At the heart of this mode of analysis is the mapping of fundamental similarities between cases, i.e. the causal regularities common to all the cases included in the comparison. On that basis, it is then hoped to arrive at comprehensive and empirically secured theories with explanatory strength so that they can be applied to, and yield insights into, other similar cases. Furthermore, Tilly (1984: 98) mentions the two theories of industrialism developed by Rostow and Gerschenkron (see above) as clear examples of this kind of comparative analysis that, in accordance with principles of natural history, seek for regular causal patterns with ordered sequences of the historical transition in question.

The classical work of Skocpol (1979) on social revolutions represents a typical example of comparative studies that seek to go beyond observing the extent to which the compared units differ or are similar, and instead aspire to tab the potential of the method for theory construction. Developing her approach in a spirit of strong opposition to psychological accounts of revolutions, Skocpol adopts a macro-historical approach, dismissing the kind of analysis that locates the origins of revolutions in the desires of revolutionaries to overthrow the state. She instead turns to the structures of these states and looks for the particular vulnerabilities that can be crucial for the revolutionary outcomes of political conflicts. Furthermore, Skocpol (1979: 24) emphasises the international and world-historical context of revolutions, an aspect that "no valid theoretical perspective on revolutions can afford to ignore." Given this particular dimension, she (1979: 33) defines social revolution as "rare occurrences in modern world history" that take place only "in particular ways in unique sets of socio-structural and international circumstances;" They are "rapid, basic transformations of a society's state and class structures, accompanied and in part carried through by class-based revolts from below."

However, the main point here is that more than looking for some rough orientations of the kind suggested by Moore, Skocpol uses the comparative analysis to develop a general causal theory of social revolutions, i.e. a theory with the general claim of fitting any case of social revolution. Comparing the French, Russian and Chinese revolutions, she (1976: 178) thus proposes a general causal model according to which a social revolution can be accounted for in terms of a conjuncture of three developments: 1) the collapse or incapacitation of central administrative and military machineries, 2) widespread peasants rebellions; and 3) marginal elite political movements. Moreover, what each such revolution minimally leads to is "the extreme rationalisation and 
centralisation of state institutions, the removal of a traditional landed upper class from intermediate (regional and local) quasi-political supervision of the peasantry, and the elimination or diminution of the economic power of a landed upper class."

It should also be mentioned that long before Skocpol, Cane Brinton used comparison to study revolutions aspiring to develop a more general theory. In his little book, The Anatomy of Revolution from 1938, he sought to find some fundamental similarities between four major revolutions, namely the English, American, French, and Russian ones and sketched "some tentative uniformities" found is all four old regimes: 1) each one of these societies were experiencing some considerable economic expansion prior to the revolution and the groups most actively participating in the making of revolution were not typically or generally those most harmed by this expansion; 2) Each one of these old societies was torn by bitter class antagonisms; 3) significant numbers of intellectuals had transferred their allegiances away from the old regime; 4) the governmental machinery had grown inefficient; and finally, 5) the old ruling classes had lost confidence in themselves and their traditions.

Another interesting study here is the one carried out by Peter Kolchin, namely Unfree Labor from 1987, which is a comparative study of two systems of human bondage, American slavery and Russian serfdom, existing at approximately the same time outside the old world. Although specific and sharply differing historical conditions dictated the establishment of these two systems of forced labour, nonetheless Kolchin carries out this comparison in hope of helping him assess the relative weigh of various variables and thereby "distinguish the specific or incidental from the general or inherent" (1987: ix). In other words, while these two systems are by no means seen as identical, Kolchin hopes however that the comparison will "reduce the parochialism inherent in single-case studies" helping him to transcend their particularities and get hold of what can be generalisable.

It should also be added that a less ambitious but nonetheless important function of this kind of comparative analysis is to serve the purpose of criticism, i.e. to help us test the existing causal theories or hypotheses, providing further support for the true ones while revealing the false ones. Moreover it is used to demonstrate the limits to the validity of a theory by showing its shortcomings to explain the new cases. A good example here is Kocka's (1980) study of the so-called white-collar employers and other petite bourgeois groups with regards to their difficulties in coping with modern industrial society and their subsequent inclination to support extreme right-wing politicians. Comparing Germany with some other Western nations, Kocka argues that these groups in Germany are more privileged by governments and employers over the blue-collar workers, as compared to their American, British, and French counterparts. On this basis he is thus inclined to dismiss the general validity of the assumed correlation between crisis in capitalism and the rise of fascism.

To close this section, some words should also be said about the fact that, like in any other typology, the various types of comparative analysis mentioned above represent ideal-type categories discerned or constructed in order to bring out more efficiently the differences between various comparative strategies. In real practice, however, this kind of analytical separation is almost impossible to do as most comparative studies show a mixture of these strategies, aiming at both revealing the underlying generalities as well as understanding the compared units more sharply as their individuality is illuminated in the comparative light.

\section{Limits of Historical Comparison}

The widespread use of comparison can easily cause the impression that this method is a firmly established, smooth and unproblematic mode of analysis, which due to its unquestionable logical status can generate reliable knowledge once some technical preconditions are met satisfactorily. Yet, as we have already seen, comparison is a quite demanding method strategy that requires reflection and careful consideration. Indeed, there are a number of severe limitations and constraints associated with comparison that, calling for serious attention, should warn against and prevent any easy-minded uncritical adoption of this mode of analysis. Any comprehensive and detailed discussion of these limitations and constraints would, however, require a treatment that exceeds the scope of this paper by far. Therefore, in this section only a couple of very elementary issues are taken up for discussion while many other important aspects of the question are left out.

One of the most basic issues here regards the autonomy of units chosen for comparison. As various species of entities are picked up to be compared, there is often an underlying and tacit assumption about their autonomy and a silent tendency to ignore the complex interplays and mutual influences among the units. Facing this difficulty, i.e. the absence of enough independent, self-contained cases to be compared in order to identify causal patterns, the researcher is thus often left with a substitute, namely that of narrating a story instead. To illustrate the point let us take an example. In his major work, The Sources of Social Power, Michael Mann (1986: 502-3) ponders over the possible causes behind the rise of the West and stagnation of other civilisations. In this context he spends a few moments on alternative, and potentially possible historical outcomes that nonetheless remained 
unrealised. He then goes on and discusses some of the difficulties in arriving at a definite causal explanation and, among other things, points at the interplay among the compared units as a sever obstacle in developing causal accounts. According to him, since none of these cases was autonomous and detached from the mutual influences that constantly flowed across them, it is hard to identify any tidy indigenous causal patterns. (Note 3)

On this basis he then holds that "the comparative method has no solution to these problems, not because of any general logical or epistemological defects it might have but because, in dealing with the problems we simply do not have enough autonomous, analogous cases. Confronted by that empirical reality, we must turn pragmatically to the second method, of careful historical narrative, attempting to establish 'what happened next' to see if it has the 'feel' of a pattern, a process, or a series of accidents and contingencies. Here we still need explicit but broad concepts and theories about how societies generally work and about how human beings behave, but we employ them in historical narrative, looking for continuity or conjecture, pattern or accident."

Another fundamental issue with far-reaching implications concerns the choice of the units being compared. The main point is that, far from being an innocent and/or simple task, the choice of comparison units is a critical and tricky issue. This point has been observed by many, among them Kocka who, drawing on the experiences form the case of the so-called Sonderweg thesis, puts the issue as follows. According to him (1999:49), this case "makes extremely clear the degree to which the results of a comparison depend on the selection of the objects of comparisons. Compared with its Dutch or English parallels, the nineteenth century German economic bourgeoisie appears relatively limited in extent, power, and bourgeois qualities. But compared with east-central or eastern European countries, it appears strong and intensely bourgeois. The Western comparative perspective makes National Socialism appear deviant; from a southern or south-eastern European perspective, Nazism becomes part of a phenomenon spread across large parts of the continent." Therefore, Kocka continues by urging us not to omit the consequences of the "selectivity of comparison" and suggests that in many cases "changing the partner compared can make this selectivity conscious and can mitigate the gross (potential) distortions."

Moreover, as we have seen, one of the main reasons for the use of comparison is exactly the small number of the cases of the phenomenon under study. In other words, it is typically the absence of large enough number of cases that prevents the analyst from using the conventional statistical methods. In consequence, comparative studies often embrace only a handful of cases, which in a sense are not chosen freely by the analyst but rather make up a given premise in his or her approach simply because they are the only ones available. That one in his or her research is confined to a small number or, as it often is, to a few cases is of course a serious limitation and constitutes an inherent bias in the structure of comparison, with far reaching implications for the validity of the outcomes of these studies especially with regards to their generality.

This issue deserves due attention especially because every comparative study begins with certain, tacit or outspoken, assumptions about comparability of the chosen units, i.e. the assumption that suggests that it is, at some level of analysis, meaningful to compare these units in some certain aspect or along some particular dimension. Against this background, crucial questions to be addressed seriously are: in what respect and to what extent these given units are really comparable; what conditions are required to make any comparison among them meaningful; how we are to safeguard ourselves against the pitfalls in comparing incomparable units belonging to different contexts; and what are the alternative comparisons that could be carried out with possibly different sets of units, pointing at possibly different conclusions.

A closely related matter, and perhaps a consequence of the above, is the issue of asymmetrical comparison. Since the choice range is often radically circumscribed, the analyst is often left with a small number of cases determined by factors beyond his or her power. Under these more or less imposed research conditions, it is often the case that the analyst is forced to conduct a comparison among units not of all of which he or she has equally adequate knowledge. In turn, this fact often tends to undermine or at least weaken the possibilities of conducting a balanced comparison, i.e. a comparison characterised by equally precise and equally comprehensive attention paid to all the units compared. Put differently, the narrowed options of choice of units joined with the asymmetry of competence may be the main reason accounting for the relative abundance of asymmetrical comparative studies in the human and social sciences.

As mentioned earlier, asymmetric comparative studies frequently tend to investigate one case carefully while limiting themselves to a mere sketch of the other cases, which serve as comparative reference points. More often than not, the researcher lacks sufficient knowledge about these other cases and is forced to rely heavily upon selected secondary sources the worth of which he is not capable of assessing properly. Max Weber's famous study of the Protestant ethics can serve as an extremely illustrative example (see above). As a researcher interested in the question of the rise of the West he is studying a case that represents a historical singularity, i.e. a 
unique case that nonetheless has to be compared with a given set of other civilisations of which he does not have any significant amount of knowledge and thus has to rely on the authority of other scholars, without being able to assess their scholarship in any proper way.

Against this one may thus argue that despite the obvious benefits of such a comparative design, it nonetheless is of rather doubtful value. The problem with this kind of comparison is that in such studies the descriptions of the cases chosen for comparison with the main one tend to become excessively simplified, superficial and stylised with distorted arguments and conclusions as entailment. One is almost tempted to share Kocka's scepticism and assume that "this form of comparison proves particularly clearly the dependence of knowledge on the (selection of) comparison partner, which as a rule is selected not only on scientific criteria" (1996: 203) but rather on the basis of "normative priorities and conventions" (1999: 40), thus "abusing the units of comparison" (1999: 49). (Note 4)

However, there is also another and somewhat deeper sense of the asymmetric comparison that regards the degree to which the compared cases belonging to different socio-cultural or historical contexts are understood by the analyst. It is often held as one of the decisive merits of the comparative analysis that it allows the 'outsider' to look into a different context than his or her own with fresh eyes and thereby see things invisible to the native researcher. This is of course a strong argument for the use of comparison, especially when one recalls that the familiar world often represents itself to the native observer as self-evident and conceals its arbitrariness, making thus necessary a break with his or her 'natural attitude' towards the familiar world - a break that nonetheless is not always easy to do. Yet the problem that still lingers on and remains unsolved is the following: To what extent it is possible for a researcher to penetrate into a different context, get acquainted with the universe of meaning pertinent to that context and acquire the relevant insights that are sufficiently deep to put him or her in the position of comparing the unfamiliar worlds of others with his or her own.

The problem of asymmetric understanding is in itself an old epistemological problem that has been discussed by many and in a variety of ways (see for instance Fay 1996, Ch 1). Sufficient to mention here is that, unlike the case with the natural sciences, the subject matter of humanities and social sciences are purposeful, intentional and meaning-creating actors and any account of what comprise their social lives - i.e. their perceptions, actions, relations and activities- requires an adequate understanding of the meanings produced and mediated thereby. In other words, when a researcher is examining phenomena that belong to fields far from home, he or she should have the ability to take head of the particularities of the terrain under his or her feet, have the sensitivity that enables him or her to penetrate beneath the apparent similarities and grasp the context-specific meanings attached to the phenomena under observation.

It is not however the argument of this paper to advocate the so-called immensurability of cultural differences, i.e. the notion suggesting the impossibility of cross-cultural understanding. Rather, the point that is wished to be stressed here is that such an understanding is an extremely demanding and time-consuming task that should be sought after with sufficient amount of seriousness. Furthermore, the problem of asymmetric understanding is indeed one of the primary concerns of comparative analysis with important implications that are relevant not only for asymmetric kind of comparison but for all comparative strategies and especially for the comparative approaches designed to find general, cross-contexts-valid causal explanations.

This point is put by Robert Anderson, et al. (1986), for instance, who draw on Peter Winch's (1958) problematisation of the very concept of 'sameness' and the difficulties associated with discerning the same phenomena across what he called various 'forms of life.' On this basis, the authors argue that, in pursuing to compare like with like, comparative research requires the particular ability of recognising sameness or similarity of phenomena across various contexts. Following the lead offered by Winch, Anderson et. al. (1986: 184) maintain for instance that "in order to decide which institutions of one society - our own in many cases- to compare with those of another we shall need to be able to match those institutions, to say what kind of part they play in their respective society ... However, if we are in a position to say what part each institution plays in the life of its society then we have already achieved a very good understanding of it."

One may argue, of course, that deep-level cross-cultural understanding is not called for in all comparative research and hold that there can be, and are, many comparative studies, especially within the filed of political science, that do not necessarily delve into the socio-cultural contexts of the phenomena they examine. Many of such studies stay instead at such a level where many categories and concepts can be used across contexts with no or only minor adjustments. Or, according to this argument, there can be constructed many context-independent concepts that, capturing the universal essence of the phenomena they label, can be used to observe, measure and thus compare the same underlying phenomena across widely various cultures. Many examples of cross-national 
studies using conventional survey analysis run into mind here, like the comparative studies of party membership, participation in general elections, size of public sector or expenditures, distribution of high political offices among different age-groups, sexes, minorities, etc.

The very notion of the possibility of designing categories and measurements valid across various settings may suggest a solution to the problem of asymmetric comparison, and indeed the field of political science and many other disciplines abound with examples of trans-national comparative studies using the conventional variable analysis to compare various statistically designed measures. Yet, what is omitted here appears to be the fact that the enterprise of comparing even the apparently most straightforward phenomena across contexts with largely similar structures turns out to require far-reaching considerations about national differences in defining, categorising, and measuring apparently common phenomena like savings, and unemployment, let alone more complicated concepts like political engagement, participation, organisation and mobilisation. (Note 5)

An illustrative example here, which is of particular interest to political science, is Tilly's (1984b) idea of the repertoire of collective action. By this notion, he means the set of means, which is available to, and used by, the members of a group for making claims and struggling for them. This repertoire consists of, in other words, action alternatives that seem of feasible to the group, has greater legitimacy and are more frequently deployed by the group. According to Tilly, the Western European repertoire that evolved in the nineteenth century includes typically strikes, electoral rallies, demonstrations, petition marches and all kinds of public assemblies, often relying on and requiring some kind of formal organisation like trade unions, political parties, voluntary associations, etc. Elaborating on this notion, Ann Swidler (1986) argues that different cultures are marked by different repertoires or 'took kits' for collective, often political, action. According to her, each culture provides a limited set of resources out of which groups and individual actors construct a number of styles of collective action. In each culture there is thus a limited pool of strategies and modes of organising collective action, sometimes deeply institutionalised, and the point is that this set is culturally variable, i.e. it may vary greatly from one culture to another.

What all this amounts to? Given the fundamental problems with the import-mirror view or the individualising comparison, one is hesitant to attach to this design of comparative research any other function than the general reflective ones discussed above. Given the lack of due attention to the particularities of contexts characterised by the theory-development view or the universalising comparison, it is very doubtful if one can confidently endorse the use of comparative approach to discover general causal theoretical constructions, although some limited functions of hypothesis testing and assessment of applicability range of a theory can be important potentials of this mode of comparative design. Against this, one is thus left with the second type, namely the difference view, the divergent comparison or the variation finding comparison as the only scientifically reliable method strategy.

In other words, it appears that if comparison is to be used it cannot be done in any other way than what suggested by John Stuart Mill (1950: 211-216) long time ago, namely as a method of difference and a method of agreement. Rather than seeking general causal explanations, comparative analysis seem to be capable of offering no more than illustrations demonstrating fruitfulness and shortcomings of theories and models developed otherwise, to show the boundaries of their applicability. As such, comparative method can be used confidently only in the fashion suggested by Moore, i.e. as a rough check on our theories and models, preventing us from going astray and simultaneously stimulating our theoretical imagination, which nonetheless is much needed for the elaboration of these theories and models.

\section{Concluding Suggestions}

Any comparison is a construction in the sense that it discerns which elements or segments of social reality are to be related to one another and along what dimensions. It selects particular units and/or aspects rather than others, and abstracts them from the context in which they are indiscernibly embedded. It, in other words, brings into fore what is otherwise hidden in the totality of social reality - a reality that in its totality appears as infinite, formless and chaotic. As a construction, comparison thus helps create an ordered perception of this reality, i.e. an organised way to see it in one way rather than in many other alternative ways. Therefore, it should be reflected on, brought into the sphere of awareness, rather than deployed as if it were an unproblematic and self-evident mode of analysis.

Furthermore, since comparison organises perception in one way rather than another, one should also be conscious of the kind of order it yields. Not seldom comparative approach is used by researchers to establish a certain new order of things and/or to reinforce the old ones. Underneath Kocka's dissatisfaction with the abuse of 'other' cases in order to show the particularity of the main case lies this often-used potential of comparative analysis to elaborate and establish hierarchical orders in which civilisations, cultures, societies, and nations are 
nested, either as cases that are in some respect inferior to the favoured ones or as abnormalities and/or deviations of some path or model that, represented by the favoured cases, is taken to serve as the normality or the point of reference in the comparison.

Yet, comparison is still a method with outstanding merits, chiefly because of its ability to make us recognise the narrowness of our mind and check against the shortcomings and harmful consequences of localism and provincialism. We may however have something to learn from historians' hesitation in using comparison and from their respect for the uniqueness of contexts and histories of peoples. One may hope that comparative mode of analysis can be broadened, not only comparing structures, institutions and processes, but also mentalities, experiences, emotions, codes and symbols. More importantly, one may also hope for a greater respect for particularities of societies and cultures, i.e. the most profound promise of the comparative analysis, namely to reveal the multiplicity of social worlds, the particularities of the researcher's own society as well as those of others.

\section{References}

Allik, Juri \& Realo, Anu \& Mottus, Rene \& Borkenau, Peter \& Kuppens, Peter \& Hrebickova, Martina. (2010). How People See Others Is Different From How People See Themselves: A Replicable Pattern Across Cultures. Journal of Personality and Social Psychology, 99:870-82.

Anderson, Robert J., John A. Hughes \& Wesley W. Sharrock. (1986). Philosophy and the Human Sciences. London: Routledge.

Bendix, Reinhard [1964]. (1977). Nation Building and Citizenship: Studies of Our Changing Social Order. Berkeley, CA: University of California Press.

Bendix, Reinhard. (1978). Kings or Peoples: Power and the Mandate to Rule. Berkeley, CA: University of California Press.

Black, Cyril E. (1967). Dynamics of Modernization: A Study in Comparative History. New York: Harper \& Row Brinton, Crane [1938]. (1965). The Anatomy of Revolution New York: Vintage.

Drobni, Sonja \& Beham, Barbara \& Prag, Patrick. (2010). Good Job, Good Life? Working Conditions and Quality of Life in Europe. Social Indicators Research, 99: 205-25.

Droogers, Andre. (2005). Syncretism and Fundamentalism: A Comparison. Social Compass, 52: 463-71.

Durkheim, Emile [1897]. (1951). Suicide: A Study in Sociology. Glencoe, IL: The Free Press.

Durkheim, Emile [1895]. (1982). The Rules of Sociological Method. London: MacMillan.

Esping-Andersen, Gösta (1990). The Three Worlds of Welfare Capitalism. Cambridge: Polity.

Fay, Brian. (1996). Contemporary Philosophy of Social Science: A Multicultural Approach. Oxford: Blackwell.

Fredrickson, George M. (1997). The Comparative Imagination: On the History of Racism, Nationalism, and Social Movements. Berkeley, CA: University of California Press.

Gerschenkron, Alexander [1962]. (1966). Economic Backwardness in Historical Perspective: A Book of Essays. Cambridge, MA: Belknap Press.

Goldstone, Jack A. (1991). Revolution and Rebellion in the Early Modern World. Berkeley: University of California Press.

Green, Nancy L. (1997). Ready-to-Wear and Ready-to-Work: A Century of Industry and Immigration in Paris and New York. Durham: Duke University Press.

Hedström, Peter \& Richard Swedberg. (1998). Social Mechanisms: An Analytical Approach to Social Theory. Cambridge: Cambridge University Press.

Janoski, Thomas \& Alexander M. Hicks. (1994). Methodological Innovations in Comparative Political Economy: An Introduction, pp. 1-7, in The Comparative Political Economy of the Welfare State, edited by Thomas Janoski and Alexander M. Hicks. Cambridge: Cambridge University Press.

Kindleberger, Charles P. (2000). Comparative Political Economy: A Retrospective. Cambridge, MA: MIT Press.

Kocka, Jurgen. (1980). White Collar Workers in America 1890-1940: A Social-political History in International Perspective. London: Sage. 
Kocka, Jurgen. (1996). The Use of Comparative History, pp. 197-209 in Societies Made up of History: Essays in Historiography, Intellectual History, Professionalizations, Historical Social Theory and Proto-Industrialization, edited by Ragnar Björk \& Karl Molin, Stockholm.

Kocka, Jurgen. (1999). Asymmetrical Historical Comparison: The Case of the German Sonderweg. History and Theory, 38: 40-50.

Kolchin, Peter. (1987). Unfree Labor: American Slavery and Russian Serfdom. Cambridge, MA: Harvard University Press.

Lipset, Seymour M. (1996). American Exceptionalism: A Double-edged Sword. New York: W. W. Norton.

Magun, Vladimir \& Rudnev, Maksim. (2010). The Life Values of the Russian Population: Similarities and Differences in Comparison with Other European Countries. Russian Social Science Review, 51: 19-73.

Mann, Michael. (1986). The Sources of Social Power. Vol. I. A History of Power from the Beginning to A. D. 1760. Cambridge: Cambridge University Press.

May, Tim. (1993). Social Research: Issues, Methods and Process. Buckingham: Open University Press.

Merkin, Rebecca \& Ramadan, Reem. (2010). Facework in Syria and the United States: A cross-cultural comparison. International Journal of Intercultural Relations, 34: 661-69.

Mill, John Stuart. (1950). Philosophy of Scientific Method. New York: Hafner.

Moore, Barrington. (1966). Social Origins of Dictatorship and Democracy. London: Penguin Books.

Ragin, Charles C. (1987). The Comparative Method: Moving beyond Qualitative and Quantitative Strategies Berkeley. LA: University of California Press.

Rostow, Walt W. (1960). The Stages of Economic Growth: A Non-communist Manifesto. Cambridge: Cambridge University Press.

Shalev, Michael (ed.). (1996). The Privatization of Social Policy? Occupational Welfare and the Welfare State in America, Scandinavia and Japan. Basingstoke: Macmillan.

Skocpol, Theda. (1979). States and Social Revolutions: A Comparative Analysis of France, Russia and China. Cambridge: Cambridge University Press.

Skocpol, Theda \& Margaret Somers. (1978). The Uses of Comparative History. Comparative Studies in Society and History, 22: 174-97.

Smelser, Neil J. (1976). Comparative Methods in the Social Sciences. Englewood Cliffs, NJ: Prentice-Hall.

Suzuki, Shinobu. (2010). Forms of written arguments: A comparison between Japan and the United States. International Journal of Intercultural Relations, 34: 651-60.

Swidler, Ann. (1986). Culture in Action: Symbols and Strategies. American Sociological Review, 51: 273-86.

Taylor, Ian (ed.). (1999). The Social Effects of Free Market Policies: An International Text. London: Harvester Wheatsheaf.

Tilly, Charles. (1984). Big Structures, Large Processes, Huge Comparisons. New York: Russell Sage Foundation.

Tilly, Charles. (1984b). Social Movements and National Policies, pp. 297-317 in Statemaking and Social Movements: Essays in History and Theory, edited by Charles Bright and Susan Harding. Ann Arbor: The University of Michigan Press.

Tilly, Charles. (1993). European Revolutions 1492-1992. Oxford: Blackwell.

Tocqueville, Alexis de [1835 \& 1840]. (1945). Democracy in America. New York: Knopf and Random House.

Tocqueville, Alexis de [1856]. (1955). The Old Regime and the French Revolution. Garden City, NY: Doubleday Anchor.

Weber, Max [1920]. (1996). The Protestant Ethics and the Spirit of Capitalism. Los Angeles: Roxbury.

Winch, Peter [1958]. (1990). The Idea of a Social Science and Its Relation to Philosophy. London: Routledge.

\section{Notes}

Note 1. The fourth type of comparison in May's typology, i.e. the prediction view, represents a category of comparative studies with the ambition of predicting the outcomes of social processes. According to this view, 
not only can the potential for the alternative outcomes of these processes be identified but also predicted, once experiences of their effects in other settings is examined. To my knowledge, this type of comparative analysis is very rare. In what follows, however, this category is left out both because of its rarity and the implausibility of the very notion of prediction in case of social reality.

Note 2. It must however also be noticed that in this study Esping-Andersen pursues a more ambitious project, namely elaborating a causal explanation of the similarities and differences among them and works out an original theoretical framework for contemporary changes in welfare states.

Note 3. With reference to the European miracle debate, Mann (1986: 503) writes, "The comparative method has no solution to these problems [i.e., the problems of identifying autonomous cases], not because of any general logical or epistemological defects it might have but because, in dealing with the problems we simply do not have enough autonomous, analogical cases. Confronted by that empirical reality, we must turn pragmatically to the second method, of careful historical narrative, attempting to establish 'what happened next' to see if it has the 'feel' or a pattern, a process, or a series of accidents and contingencies."

Note 4. Similar experience from the way Russia is often compared with the West, with the latter as a point of reference, can easily be found in political scientific literature.

Note 5. One should also take into account the point that the general value of conventional survey analysis has increasingly been questioned. As recent debate has been addressing the issue enthusiastically, this mode of survey analysis is hardly capable of producing more than, at best, shallow descriptions of correlations among some observed variables without being of much assistance in unearthing causal patterns among these variables (see Hedström \& Swedberg 1998). 